\title{
Traumatic brain injury and intracranial hemorrhage-induced cerebral vasospasm: a systematic review
}

\author{
Fawaz Al-Mufti, MD, ${ }^{1,2}$ Krishna Amuluru, MD, ${ }^{2}$ Abhinav Changa, BA, ${ }^{2}$ Megan Lander, BA, ${ }^{2}$ \\ Neil Patel, BA, ${ }^{2}$ Ethan Wajswol, BS, ${ }^{2}$ Sarmad Al-Marsoummi, MBChB, ${ }^{5}$ Basim Alzubaidi, MD, ${ }^{1}$ \\ I. Paul Singh, MD, MPH, ${ }^{2,4}$ Rolla Nuoman, MD, ${ }^{3}$ and Chirag Gandhi, MD ${ }^{2-4}$
}

\begin{abstract}
1Department of Neurology, Rutgers Robert Wood Johnson Medical School, New Brunswick; Departments of 2Neurosurgery, ${ }^{3}$ Neurology, and ${ }^{4}$ Radiology, Rutgers University, New Jersey Medical School, Newark, New Jersey; and 5 University of North Dakota, Grand Forks, North Dakota
\end{abstract}

OBJECTIVE Little is known regarding the natural history of posttraumatic vasospasm. The authors review the pathophysiology of posttraumatic vasospasm (PTV), its associated risk factors, the efficacy of the technologies used to detect PTV, and the management/treatment options available today.

METHODS The authors performed a systematic review in accordance with the PRISMA (Preferred Reporting Items for Systematic Reviews and Meta-Analyses) guidelines using the following databases: PubMed, Google Scholar, and CENTRAL (the Cochrane Central Register of Controlled Trials). Outcome variables extracted from each study included epidemiology, pathophysiology, time course, predictors of PTV and delayed cerebral ischemia (DCl), optimal means of surveillance and evaluation of PTV, application of multimodality monitoring, modern management and treatment options, and patient outcomes after PTV. Study types were limited to retrospective chart reviews, database reviews, and prospective studies.

RESULTS A total of 40 articles were included in the systematic review. In many cases of mild or moderate traumatic brain injury (TBI), imaging or ultrasonographic studies are not performed. The lack of widespread assessment makes finding the true overall incidence of PTV a difficult endeavor. The clinical consequences of PTV are important, given the morbidity that can result from it. DCI manifests as new-onset neurological deterioration that occurs beyond the timeframe of initial brain injury. While there are many techniques that attempt to diagnose cerebral vasospasm, digital subtraction angiography is the gold standard. Some predictors of PTV include SAH, intraventricular hemorrhage, low admission Glasgow Coma Scale (GCS) score $(<9)$, and young age (<30 years).

CONCLUSIONS Given these results, clinicians should suspect PTV in young patients presenting with intracranial hemorrhage (ICH), especially SAH and/or intraventricular hemorrhage, who present with a GCS score less than 9. Monitoring and regulation of CNS metabolism following $\mathrm{TBI} / \mathrm{ICH}$-induced vasospasm may play an important adjunct role to the primary prevention of vasospasm.

https://thejns.org/doi/abs/10.3171/2017.8.FOCUS17431

KEY WORDS traumatic intracranial hemorrhage; posttraumatic vasospasm; traumatic brain injury

$\mathrm{T}$ HE incidence and impact of traumatic brain injury (TBI) within the general population have increased over the past few years. ${ }^{6}$ Although the primary injury associated with TBI may be debilitating, secondary injury associated with posttraumatic arterial vasospasm is an important and dangerous consequence of TBI. The incidence of vasospasm in aneurysmal subarachnoid hemorrhage (aSAH) has been extensively studied; less is known regarding the epidemiology of posttraumatic vasospasm (PTV), with the largest study examining only 299 patients. ${ }^{25}$ Because of limited studies and small numbers of enrolled patients, PTV continues to be poorly characterized. Current literature suggests that PTV portends a more severe neurological injury, but its magnitude is un-

ABBREVIATIONS aSAH = aneurysmal SAH; CBF = cerebral blood flow; $\mathrm{CTA}=\mathrm{CT}$ angiography; $\mathrm{CTP}=\mathrm{CT}$ perfusion; $\mathrm{DCl}=$ delayed cerebral ischemia; $\mathrm{DSA}=$ digital

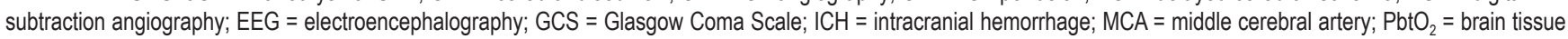
oxygen; PTV = posttraumatic vasospasm; SAH = subarachnoid hemorrhage; TBI = traumatic brain injury; TCD = transcranial Doppler.

SUBMITTED June 30, 2017. ACCEPTED August 11, 2017.

INCLUDE WHEN CITING DOI: 10.3171/2017.8.FOCUS17431. 
known. Oftentimes, surveillance for PTV is not routinely performed during management of TBI. This is in sharp contrast to the management of aSAH, where signs and symptoms of neurological deterioration are frequently uncovered due to surveillance (such as transcranial Doppler [TCD] ultrasonography and repeat CT angiography [CTA]/ $\mathrm{CT}$ ), and the well-established correlation between aSAH and vasospasm. In this review, we examined the natural history of PTV and review the pathophysiology and efficacy of detection technologies, as well as management and treatment options.

\section{Methods}

\section{Search Strategy and Study Eligibility}

An electronic search of literature published between 1989 and 2016 was performed using PubMed, Google Scholar, and CENTRAL (Cochrane Central Register of Controlled Trials) in accordance with the PRISMA (Preferred Reporting Items for Systematic Review and Meta-Analysis) statement. Search terms used in various combinations included "vasospasm," "subarachnoid hemorrhage," "post-traumatic vasospasm," "traumatic brain injury," "epidemiology," "pathophysiology," "treatment," "management," "predictors," "incidence," "risk factors," "digital subtraction angiography," "computed tomography angiography," "computed tomography perfusion," "electroencephalography," "transcranial Doppler ultrasonography," "brain tissue oxygenation," "microdialysis," "thermal diffusion flowmetry," and "jugular bulb oximetry." Eligibility for this review was restricted to articles in the English-language literature. Selected study designs were limited to retrospective chart reviews, database reviews, and prospective studies. No restrictions were made based on publication date. All studies used were peer reviewed, published, and conducted in humans. One reviewer (A.C.) conducted the search, which was verified by 3 other reviewers (M.L., E.W., N.P.). The focus was on the pathophysiology of PTV, associated risk factors, and the efficacy of modern detection/treatment approaches. Studies not pertinent to the scope and intent of this review were excluded.

\section{Data Extraction}

Data on epidemiology, pathophysiology, time course, predictors of PTV and delayed cerebral ischemia (DCI), optimal means of surveillance/evaluation of PTV, applications of multimodality monitoring (such as brain tissue oxygenation, microdialysis, thermal diffusion flowmetry, and jugular bulb oximetry), modern management and treatment options, and patient outcomes after PTV were collected. Other variables included country of origin, study type, and year of publication.

\section{Quality Evaluation}

The first author (F.A.) independently evaluated all included studies for quality using the 2011 Oxford Centre for Evidence-Based Medicine Levels of Evidence (http:// www.cebm.net/ocebm-levels-of-evidence/). In this schema, the highest level of evidence for a study is a systematic review of randomized controlled trials (Level 1), followed by random trials or observational studies with dramatic effect (Level 2), and nonrandomized controlled cohort/ follow-up studies (Level 3). Lower levels of evidence are given to case series, case-control studies or historically controlled studies (Level 4), and mechanism-based reasoning studies (Level 5). Due to the paucity of information regarding the subject of vasospasm following TBI, this review includes only studies of Levels 3, 4, and 5. Risk of bias assessment was not performed because of significant variability in study methodologies used in this review.

\section{Results}

\section{Search Results}

The number of articles retained at each stage of data acquisition is shown in Fig. 1. Our initial search identified 6230 studies from collective databases, with the majority being found using the key word combination "traumatic brain injury vasospasm;" 5748 articles remained after duplicates were removed, and 961 articles remained after the aforementioned eligibility exclusion criteria were applied. Based on a survey of titles and abstracts, 40 articles were pertinent and ultimately used in the analyses.

The breakdown of the 40 articles was as follows: epidemiology (3), pathophysiology (9), time course (5), predictors (5), digital subtraction angiography (DSA; 4), CTA (3), CT perfusion (3), 3 electroencephalography (3), TCD ultrasonography (3), brain tissue oxygenation (1), microdialysis (2), thermal diffusion flowmetry (2), jugular bulb oximetry (2), and treatment (7) studies. The main findings are compiled in Table 1.

\section{Epidemiology}

PTV is not routinely assessed unless there are signs or symptoms suggesting its presence, which makes determining its true incidence a difficult endeavor. Investigating the inherent risk of PTV requires clinical vigilance because $\mathrm{SAH}$, thought to be a major contributing factor in the development of PTV, is present in up to $60 \%$ of patients who have sustained a TBI. ${ }^{3}$

Angiographic studies originally reported vasospasm incidence rates between 5\% and 18.6\%. ${ }^{20}$ As neurosonography and imaging technologies have become more accessible, rates of PTV detection have increased, now ranging from $27 \%$ to $63 \%$, with a rate of $36.3 \%$ in the pediatric population. ${ }^{24}$ Although technologies such as neurosonography have allowed for increased detection of vasospasm, increasing the sensitivity of these modalities results in an increased rate of false positives. ${ }^{34}$

\section{Pathophysiology}

Many theories have been proposed concerning the pathophysiology of PTV; however, the exact mechanism remains unknown. Wilkins and Odom asserted in 1970 that PTV was mechanistically similar to vasospasm in aSAH, in which the subarachnoid blood irritates the cerebral vessels. ${ }^{37}$ However, clinical evidence shows that PTV can occur without the presence of blood in the subarachnoid space. ${ }^{14,25}$ Mechanical factors have been implicated in the pathogenesis of PTV, with in vitro studies showing that vasospasm can occur from mechanical manipulation or irritation, although experimentally it is sustained for a 


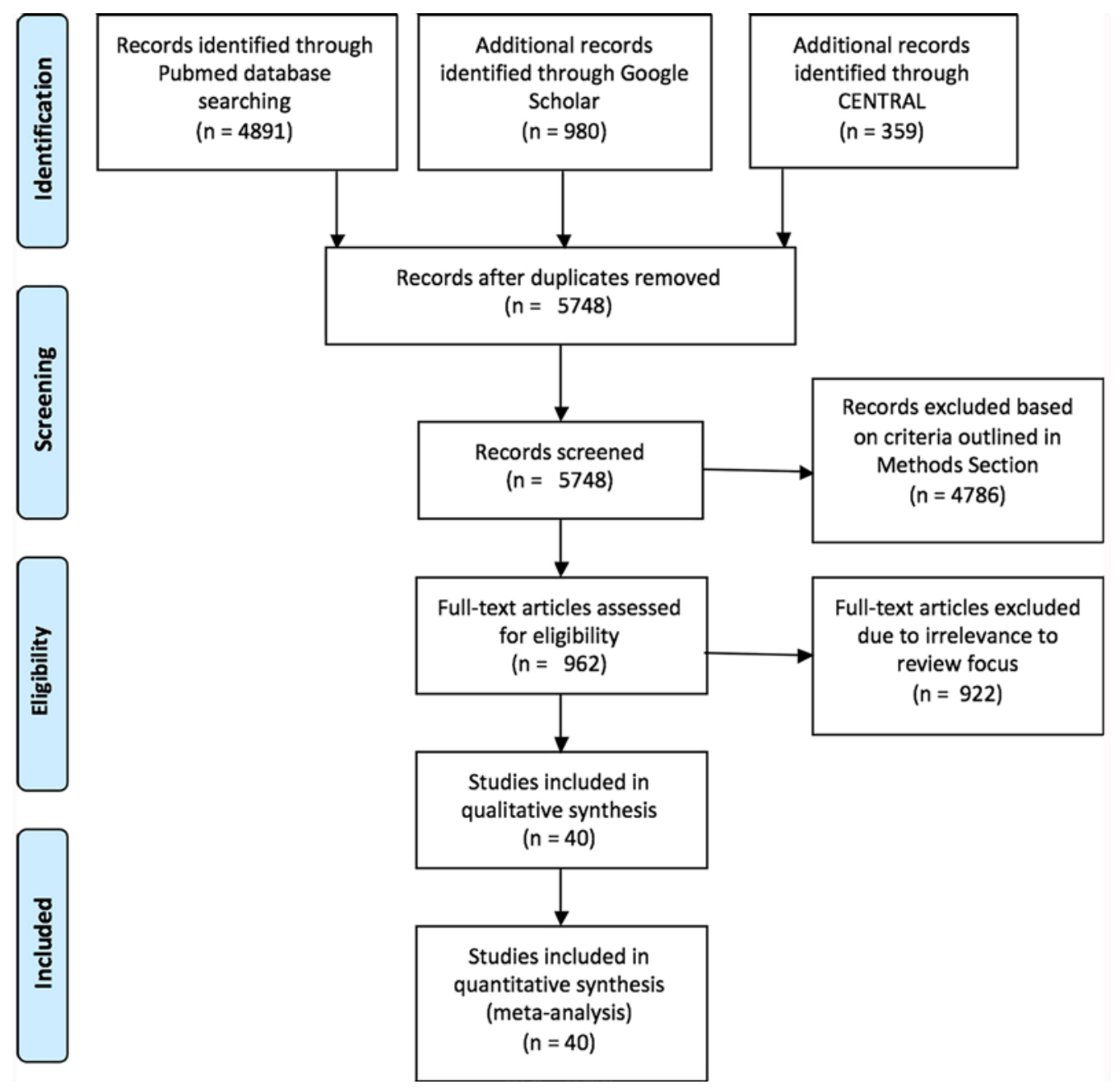

FIG. 1. PRISMA study flow diagram demonstrating the number of articles retained at each stage of data acquisition. Data added to the PRISMA template (from Moher D, Liberati A, Tetzlaff J, Altman DG, The PRISMA Group [2009]. Preferred Reporting Items for Systematic Reviews and Meta-Analyses: The PRISMA Statement. PLoS Med 6[7]:e1000097) under the terms of the Creative Commons Attribution License.

shorter time than is seen clinically. ${ }^{5,42}$ Stretching of cerebral vessels during blast injuries has also been proposed as a cause of PTV without cisternal or subarachnoid blood. ${ }^{14}$

Although the pathophysiology of cerebral vasospasm continues to be a topic of debate, there is a general consensus that spasmogenic and neuroinflammatory substances generated from lysis of subarachnoid blood propagate the process. ${ }^{27}$ Molecular models focus around endothelin-1 protein and its effect on endothelin receptor A. CSF and serum obtained in patients who have sustained a TBI show increased levels of endothelin-1, supporting its involvement in TBI and subsequent vasospasm in these patients. ${ }^{8}$

PTV results in diminished blood flow to areas of the brain, producing DCI and manifesting in new-onset neurological deterioration occurring after initial brain injury. ${ }^{21}$ Westermaier et al. found neurological evaluation to be the most accurate method for discovering vasospasm or infarction following aSAH. Unfortunately, symptoms develop much later, when intervention may not alleviate neurological dysfunction. ${ }^{36}$ It remains to be seen wheth- er these evaluation techniques are directly applicable to discovering PTV or whether different techniques may be more efficacious.

\section{Time Course}

Understanding the specific chronology of PTV relative to TBI may provide valuable information regarding optimal surveillance. Current literature shows that PTV typically occurs earlier [after TBI] than does aneurysmal vasospasm (2-3 days posttrauma vs 3-5 days post-aneurysmal vasospasm). ${ }^{12,14}$ Rarely does PTV occur as late as 6 days posttrauma. The range of PTV onset times makes it difficult for clinicians to effectively assess a patient for PTV. The duration of of PTV has been reported to last longer than 5 days in less than $50 \%$ of patients. ${ }^{24,25}$ Martin et al. distinguished traumatic SAH-related PTV from nonSAH PTV, and showed that non-SAH PTV has a shorter duration than SAH-related PTV. ${ }^{20}$ In the same study, the authors found the time course of vasospasm in traumatic SAH to be similar to that in aSAH. 
TABLE 1. Summary of PTV risk factors

\begin{tabular}{|c|c|c|c|}
\hline $\begin{array}{l}\text { Authors } \\
\& \text { Year }\end{array}$ & $\begin{array}{c}\text { Study Type } \\
\text { (no. of patients) }\end{array}$ & $\begin{array}{l}\text { Patient } \\
\text { Age in Yrs }\end{array}$ & Correlations, Conclusions, \& Effects of Risk Factors on PTV \\
\hline $\begin{array}{l}\text { Zubkov } \\
\text { et al., } \\
2000\end{array}$ & $\begin{array}{l}\text { Prospective } \\
\quad(90)\end{array}$ & $\begin{array}{l}\text { Range } \\
\qquad 14-67\end{array}$ & $\begin{array}{l}\text { Presence of epidural hematomas on CT: statistically significant increase in risk of PTV development; pres- } \\
\text { ence of subdural hematomas on CT: statistically significant increase in risk of PTV development; GCS } \\
\text { score: inverse relationship btwn score \& incidence of PTV }\end{array}$ \\
\hline $\begin{array}{l}\text { Oertel } \\
\text { et al., } \\
2005\end{array}$ & $\begin{array}{l}\text { Prospective } \\
\text { (299) }\end{array}$ & $\begin{array}{l}\text { Mean } 35 \\
\quad \text { (range } \\
16-87 \text { ) }\end{array}$ & $\begin{array}{l}\text { Younger age in population: statistically significant increase in risk of PTV development; lower GCS score: } \\
\text { statistically significant increase in risk of PTV development; presence of SAH on CT: statistically significant } \\
\text { increase in risk of PTV development }\end{array}$ \\
\hline $\begin{array}{l}\text { Armonda } \\
\text { et al., } \\
2006\end{array}$ & $\begin{array}{l}\text { Retrospective } \\
\text { chart review } \\
(57)\end{array}$ & Adults & $\begin{array}{l}\text { No. of lobes injured: statistically significant increase in risk of PTV development; presence of pseudoaneu- } \\
\text { rysm: statistically significant increase in risk of PTV development; presence of non-SAH hemorrhage: } \\
\text { statistically significant increase in risk of PTV development (grouped study of epidural, subdural, intraven- } \\
\text { tricular, or mixed hemorrhage) }\end{array}$ \\
\hline $\begin{array}{l}\text { Shahlaie } \\
\text { et al., } \\
2011\end{array}$ & $\begin{array}{c}\text { Database re- } \\
\text { view (46) }\end{array}$ & $\begin{array}{l}\text { Mean } 33.4 \\
\quad \text { (range } \\
2-92)\end{array}$ & $\begin{array}{l}\text { Fever on admission: statistically significant increase in risk of PTV development; presence of small contu- } \\
\text { sions (<1 cm) on CT: statistically significant increase in risk of PTV development; cisternal/cortical/sulcal } \\
\text { SAH on CT: statistically significant increase in risk of PTV development (NS on multivariate analysis); } \\
\text { elevated WBC count on admission: statistically significant increase in risk of PTV development (NS on } \\
\text { multivariate analysis) }\end{array}$ \\
\hline $\begin{array}{l}\text { O'Brien } \\
\text { et al., } \\
2015\end{array}$ & $\begin{array}{l}\text { Prospective } \\
\text { (69) }\end{array}$ & Children & $\begin{array}{l}\text { MVA as mechanism of injury: statistically significant increase in risk of PTV development; GCS score } \leq 8 \text { : sta- } \\
\text { tistically significant increase in risk of PTV development; ISS: statistically significant increase in risk of PTV } \\
\text { development; fever on admission of } \geq 38^{\circ} \mathrm{C} \text { : statistically significant increase in risk of PTV development }\end{array}$ \\
\hline
\end{tabular}

ISS = Injury Severity Score; MVA = motor vehicle accident; NS = not significant; WBC = white blood cell.

\section{Predictors of PTV}

PTV risk factors stem from studies that have shown a correlation between imaging findings and the incidence of vasospasm linked to each finding (Table 1). Severe SAH has consistently been linked to a high incidence of PTV, ${ }^{25,42}$ with some studies showing an increased predilection for developing PTV in cases of intracerebral hematoma. ${ }^{25}$ An increased incidence of PTV has also been reported in some cases of epidural and subdural hematomas. $^{42}$

Certain clinical presentations have also been shown to correlate with an increased risk of developing PTV. Shahlaie et al. showed that fever was independently associated with PTV. ${ }^{30}$ The Injury Severity Score has been found to positively correlate with the incidence of vasospasm in children, although this finding was not significant in adults. ${ }^{23}$ In pediatric and adult populations, the Glasgow Coma Scale (GCS) score was more likely to determine the risk of vasospasm. ${ }^{4,23,42}$ Armonda et al. examined blastrelated TBI associated with Operation Iraqi Freedom and similarly showed that as the number of cerebral lobes affected by the traumatic injury increases, the incidence of vasospasm increases, especially when 3 or more lobes are involved $(\mathrm{p}=0.012) .{ }^{4}$ In addition, the presence of an associated pseudoaneurysm or hemorrhage at presentation was significantly correlated ( $\mathrm{p}=0.05$ and 0.03 , respectively) with the development of PTV. Clinical outcomes were worse for patients who experienced cerebral vasospasm.

\section{Surveillance and Evaluation of PTV Neuroimaging}

Digital Subtraction Angiography

DSA was one of the first imaging modalities used to diagnose vasospasm in head trauma (Fig. 2). ${ }^{38}$ Over time, cerebral DSA has been performed more selectively due to its invasiveness, risk of complications, and the advancements in safer imaging technology. ${ }^{15}$ DSA remains the gold standard in vasospasm diagnosis following aSAH and may provide an option for endovascular therapeutic intervention when indicated..$^{19}$ Limitations of DSA include a total complication rate of approximately $5 \%$ and a $0.5 \%$ $1 \%$ risk of stroke. ${ }^{1}$

\section{CTA and CT Perfusion}

Extensive meta-analyses have shown that CTA scans are adept at determining the presence of severe vasospasm,,${ }^{10}$ with less efficacy in determining mild or moderate vasospasm. ${ }^{1} \mathrm{CT}$ perfusion (CTP) imaging is very effective in diagnosing vasospasm when DCI is suspected. CTP imaging demonstrates sensitivities and specificities near $90 \%$, positive predictive values of approximately $71 \%$, and negative predictive values as high as $99 \% .{ }^{39}$ Differences in certain parameters are useful in determining the presence of vasospasm; the mean transit time can be used as a screening tool due to its high sensitivity, and cerebral blood flow $(\mathrm{CBF})$ can be used as a confirmatory parameter due to its high specificity. ${ }^{35}$ Zhang et al. showed that quantitative data from CTP imaging can be used to prospectively determine if the vasospasm is severe enough to cause symptomatic changes in the patient. ${ }^{40}$ Early CTP imaging can also efficaciously stratify patients at risk for developing DCI. ${ }^{18}$

\section{Electroencephalography}

Electroencephalography (EEG) studies have shown corresponding signs of change in electrical activity after TBI, even prior to the development of neurological symptoms. ${ }^{22}$ Vespa et al. showed that $100 \%$ of the patients in 

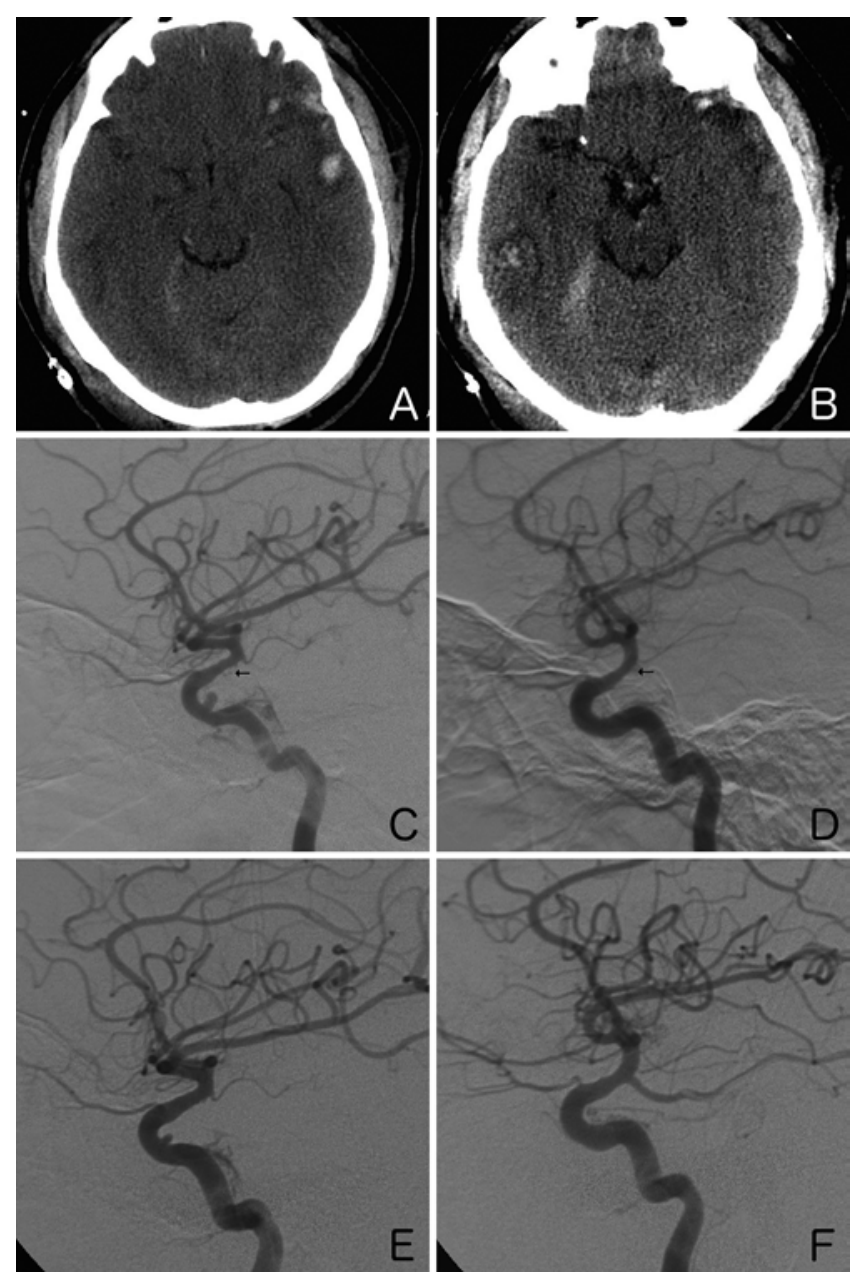

FIG. 2. Illustrative case. This 25-year-old man presented to our emergency department after an assault to the head. A: Axial noncontrast CT scan of the head showing a left temporal parenchymal hematoma with adjacent subarachnoid hemorrhage. B: Additional contrecoup right temporal parenchymal hematoma and subdural hemorrhage along the tentorium cerebelli. C and D: Right (C) and left (D) internal carotid artery (ICA) DS angiograms (lateral view) obtained on posttrauma Day 10 showing moderate vasospasm of the supraclinoid segments of both ICAs. Note the traumatic pseudoaneurysm of the cavernous right ICA as well as a traumatic right carotid-cavernous fistula. E and F: Follow-up right (E) and left (F) ICA DS angiograms (lateral views) showing resolution of vasospasm. The pseudoaneurysm was eventually treated with coil embolization.

their study with vasospasm due to aSAH had EEG findings of decreased relative alpha variability, a sign sometimes seen days prior to vasospasm diagnosed via TCD ultrasonography. ${ }^{33}$ While continuous EEG has potential as a screening tool for detecting reversible ischemia in patients susceptible to PTV, treating physicians must be aware that many confounding neurological conditions may also cause decreased relative alpha variability, i.e., increased intracranial pressure, herniation, and hemorrhage..$^{33}$

Importantly, continuous EEG monitoring can detect DCI from vasospasm before irreversible infarction of cerebral tissue occurs. ${ }^{7}$ To our knowledge, no study has examined EEG correlates of PTV to date. Although mecha- nistic differences may exist between aSAH and trauma-related vasospasm, it is possible that EEG might have some role in the detection of PTV in patients with TBI.

\section{TCD Ultrasonography}

TCD ultrasonography has been vital in guiding early management of TBI patients by monitoring the mean blood velocity and acting as a surrogate for measuring cerebral perfusion pressure. ${ }^{28}$ Currently, the overall sensitivity of TCD ultrasonography in determining vasospasm in the context of SAH ranges between $50 \%$ and $60 \%$, with both specificity and positive predictive values at $100 \%$. TCD ultrasonography has been especially successful in determining the occurrence of vasospasm in the middle cerebral artery (MCA), with sensitivity and specificity rates as high as $84 \%$ and $89 \%$, respectively. ${ }^{31}$ Sensitivity of detecting vasospasm increases as the value of the mean blood flow velocity on TCD ultrasonography increases and should be highly suspected with velocities above 200 $\mathrm{cm} / \mathrm{sec}^{16}$

\section{Multimodality Monitoring \\ Brain Tissue Oxygen Monitoring}

Brain tissue oxygen $\left(\mathrm{PbtO}_{2}\right)$ monitoring involves implantation of a probe in a brain region that is at risk for vasospasm. This method provides information on oxygenation of tissue proximal to the probe at repeated time intervals. Studies have reported that lower oxygenation levels conferred a greater risk for vasospasm. This technique is rather invasive and of questionable reliability, as it is only able to monitor a limited region, thus possibly missing other brain areas at risk for DCI. ${ }^{26}$

\section{Cerebral Microdialysis}

Cerebral microdialysis uses artificial CSF dialysate exposed by a microdialysis catheter with a semipermeable membrane to allow molecules to equilibrate down a concentration gradient. The dialysate is collected, and local levels of interstitial cerebral metabolic markers, such as glutamate, lactate, pyruvate, and glucose, are measured. ${ }^{12}$ Cerebral microdialysis provides data on levels of these markers and may detect ischemia presymptomatically with $89 \%$ specificity by examining changing levels of glutamate, glucose, and lactate. Elevated levels of taurine, lactate, and nitrate on microdialysis have been associated with poor neurological outcomes. Despite its predictive value, microdialysis is invasive and regionally limited (like $\mathrm{PbtO}_{2}$ monitoring), which may result in overlooking other brain areas afflicted with DCI. ${ }^{26}$

\section{Continuous Regional Cerebral Blood Flow Monitoring Using Thermal Diffusion Flowmetry}

This method involves inserting one heat-transmitting probe into the brain and measuring the spread of heat to another area of the brain. Heat dissipation provides insight into the tissue's ability to transport heat, which is heavily influenced by local CBF. ${ }^{29}$ Although this technique yields useful real-time data on the area of brain at risk for ischemia, like $\mathrm{PbtO}_{2}$ monitoring and microdialysis, it is limited by the relatively small region of brain it 
is able to monitor. Studies have shown this technique to be more reliable than TCD ultrasonography in detecting symptomatic cerebral vasospasm in patients with highgrade $\mathrm{SAH}$, with increasing sensitivity and specificity as $\mathrm{CBF}$ increases. ${ }^{26}$

\section{Jugular Bulb Oximetry}

In this technique, an oxygen saturation probe is inserted into the jugular vein above the facial vein, providing oxygenation data for the intracranial circulation and allowing for a more global view of cerebral perfusion compared with microdialysis and $\mathrm{PbtO}_{2} \cdot{ }^{13}$ When hemoglobin concentration, arterial oxygen saturation, and cerebral metabolic demand are maintained, jugular venous oxygenation saturation is proportional to cerebral perfusion. This technique, while somewhat invasive, is relatively safe and has been associated with negligible infection rates. One complication, however, is the risk of internal jugular vein thrombosis with prolonged use. ${ }^{26}$

\section{Contemporary Paradigms in Management and Treatment}

The goal in treating vasospasm is to prevent secondary ischemic injury to the central nervous system. Although "triple-H" (hypertension, hypervolemia, and hemodilution) therapy was previously used in managing vasospasm due to aSAH as well as PTV, this management modality has fallen out of favor. ${ }^{41}$ Triple-H therapy can cause or worsen cerebral edema, which may be more severe in trauma than in aneurysmal rupture and may worsen neurological function. ${ }^{14}$

Currently, nimodipine is the most efficacious and widely used medication in the setting of PTV . ${ }^{11}$ Nimodipine works as a calcium channel blocker by antagonizing the effect of dihydropyridine channels in smooth muscle cells. This decreases calcium influx into cells, which then decreases smooth muscle cell contractility, ultimately preventing vasospasm from occurring. ${ }^{2}$ Although some moderately sized studies have shown that nimodipine has some benefit in reducing the incidence of vasospasm, large-scale meta-analyses have shown that differences in mortality rates were not statistically significant with the addition of nimodipine. ${ }^{11}$ Stein and Le Roux proposed that there might be a role for nimodipine usage in a smaller subset of PTV cases as evidenced by a decreased incidence of vasospasm; however, this requires further investigation. ${ }^{31}$ Patients receiving calcium channel blocker therapy must be monitored for hypotension, which may cause hypoperfusion and resultant cerebral ischemia. ${ }^{41}$

Papaverine, a phosphodiesterase-III inhibitor, has shown some efficacy in reducing vasospasm. Nevertheless, the effect is short lived and vasospasm often recurs, requiring multiple intraarterial doses. Currently, less is known about the usage of papaverine than that of nimodipine; further study is required. ${ }^{2}$ Lastly, endothelin receptor blockers at high doses, such as clazosentan at $15 \mathrm{mg} / \mathrm{hr}$, displayed a reduction in vasospasm-related morbidity and all-cause mortality in the context of aSAH but did not show improved long-term functional outcomes. ${ }^{17}$ This could be due to other confounding factors, such as side effects or study design, causing apparent persistent ischemia. ${ }^{9}$ Given their novelty, further studies are required to delineate the role of endothelin receptor blockers in PTV. However, results from recent animal models show promise.

The management of vasospasm is undergoing a paradigm shift in which treating the sequelae of vasospasm rather than vasospasm itself is favored. ${ }^{26}$ Inconsistent efficacies of pharmacological agents have pushed forward monitoring and regulating CNS metabolism itself using techniques such as cerebral microdialysis and tissue oxygen monitoring rather than attempting to stop the occurrence of vasospasm. ${ }^{32}$ The results are still in their infancy but seem encouraging.

\section{Patient Outcomes}

Twelve studies provided analyses based on patient outcomes. The duration of MCA spasms lasted an average of 3-5 days. ${ }^{1,4}$ The duration of vasospasm was shorter if the anterior circulation was involved, resolving in 2.5 days. ${ }^{1}$ In pediatric patients, good neurological outcome (defined as a GCS score of $\geq 41$ month after TBI) after moderately severe brain injury was seen in $76 \%$ of patients without vasospasm but in only $40 \%$ of those with vasospasm..${ }^{15}$ Rates of good neurological outcome for severely injured patients also demonstrated worsening for those with vasospasm compared with those without (15\% vs 29\%). Regarding therapy, some medical management and interventional options have been found to provide vasospasm relief and improve outcomes. Interventionally, microballoon angioplasty in adult patients was found to significantly lower MCA and basilar artery flow velocities. ${ }^{16}$ Medically, patients treated with nimodipine had significantly lower incidences of death, vegetative survival, or severe disability at 6 months posttrauma compared with placebo. ${ }^{34}$ Patients treated with clazosentan instead had nearly equal rates of poor neurological outcome (defined as GCS score of $\leq 4$ ) and mortality rates at 12 weeks when compared with placebo. ${ }^{37}$ Clazosentan was additionally found to have higher rates of pulmonary complications, anemia, and hypotension in those patients.

\section{Conclusions}

We reviewed the current literature available on cerebral vasospasm in posttraumatic injury, focusing on the etiology of vasospasm, risk factors, surveillance and evaluation of PTV, and management options. While there are many different techniques for evaluating PTV, the gold standard for diagnosis remains DSA. We found an overwhelming majority of the literature showing an increased incidence of PTV in patients with SAH, an admission GCS score less than 9, and patient age younger than 30 years. There also seems to be an association with intraventricular hemorrhage and PTV, although to a lesser extent than with SAH. Patients copresenting with a pseudoaneurysm may also be at an increased risk for PTV. Given the results of this review, clinicians should suspect PTV in young patients presenting with intracranial hemorrhage (ICH), especially SAH and/or intraventricular hemorrhage, who present with a GCS score less than 9. Due to the inconsistent efficacies of pharmacological agents, it is suggested that monitoring and regulation of CNS metabolism following $\mathrm{TBI} / \mathrm{ICH}$-induced vasospasm may play an important adjunct role to the primary prevention of vasospasm. 


\section{References}

1. Anderson GB, Ashforth R, Steinke DE, Findlay JM: CT angiography for the detection of cerebral vasospasm in patients with acute subarachnoid hemorrhage. AJNR Am J Neuroradiol 21:1011-1015, 2000

2. Archavlis E, Carvi Y Nievas M: Cerebral vasospasm: a review of current developments in drug therapy and research. J Pharm Technol Drug Res 2:18, 2013

3. Armin SS, Colohan ART, Zhang JH: Vasospasm in traumatic brain injury. Acta Neurochir Suppl 104:421-425, 2008

4. Armonda RA, Bell RS, Vo AH, Ling G, DeGraba TJ, Crandall B, et al: Wartime traumatic cerebral vasospasm: recent review of combat casualties. Neurosurgery 59:1215-1225, 2006

5. Arutiunov AI, Baron MA, Majorova NA: The role of mechanical factors in the pathogenesis of short-term and prolonged spasm of the cerebral arteries. J Neurosurg 40:459472,1974

6. Centers for Disease Control and Prevention: Rates of TBIrelated emergency department visits, hospitalizations, and deaths - United States, 2001-2010. CDC.gov (https://www. cdc.gov/traumaticbraininjury/data/rates.html) [Accessed September 8, 2017]

7. Claassen J, Hirsch LJ, Kreiter KT, Du EY, Connolly ES, Emerson RG, et al: Quantitative continuous EEG for detecting delayed cerebral ischemia in patients with poor-grade subarachnoid hemorrhage. Clin Neurophysiol 115:2699-2710, 2004

8. Graves J, Betrus C, Rafols JA: Situating cerebral blood flow in the pathotrajectory of head trauma, in Kreipke CW, Rafols JA (eds): Cerebral Blood Flow, Metabolism, and Head Trauma: The Pathotrajectory of Traumatic Brain Injury. New York: Springer, 2013, pp 29-51

9. Graves JC, Kreipke CW: Endothelin, cerebral blood flow, and traumatic brain injury: implications for a future therapeutic target, in Kobeissy FH (ed): Brain Neurotrauma: Molecular, Neuropsychological, and Rehabilitation Aspects. Boca Raton, FL: CRC Press/Taylor \& Francis, 2015, pp 543-548

10. Greenberg ED, Gold R, Reichman M, John M, Ivanidze J, Edwards AM, et al: Diagnostic accuracy of CT angiography and CT perfusion for cerebral vasospasm: a meta-analysis. AJNR Am J Neuroradiol 31:1853-1860, 2010

11. Harders A, Kakarieka A, Braakman R: Traumatic subarachnoid hemorrhage and its treatment with nimodipine. J Neurosurg 85:82-89, 1996

12. Izzy S, Muehlschlegel S: Cerebral vasospasm after aneurysmal subarachnoid hemorrhage and traumatic brain injury. Curr Treat Options Neurol 16:278, 2014

13. Kistka H, Dewan MC, Mocco J: Evidence-based cerebral vasospasm surveillance. Neurol Res Int 2013:256713, 2013

14. Kramer DR, Winer JL, Pease BAM, Amar AP, Mack WJ: Cerebral vasospasm in traumatic brain injury. Neurol Res Int 2013:415813, 2013

15. Lee DJ, Moftakhar P, Glenn TC, Vespa PM, Martin NA: Intra-arterial calcium channel blocker infusion for treatment of severe vasospasm in traumatic brain injury: case report. Neurosurgery 63:E1004-E1006, 2008

16. Macdonald RL: Management of cerebral vasospasm. Neurosurg Rev 29:179-193, 2006

17. Macdonald RL, Higashida RT, Keller E, Mayer SA, Molyneux A, Raabe A, et al: Randomized trial of clazosentan in patients with aneurysmal subarachnoid hemorrhage undergoing endovascular coiling. Stroke 43:1463-1469, 2012

18. Malinova V, Dolatowski K, Schramm P, Moerer O, Rohde V, Mielke D: Early whole-brain CT perfusion for detection of patients at risk for delayed cerebral ischemia after subarachnoid hemorrhage. J Neurosurg 125:128-136, 2016

19. Marshall SA, Nyquist P, Ziai WC: The role of transcranial Doppler ultrasonography in the diagnosis and management of vasospasm after aneurysmal subarachnoid hemorrhage. Neurosurg Clin N Am 21:291-303, 2010

20. Martin NA, Doberstein C, Zane C, Caron MJ, Thomas K, Becker DP: Posttraumatic cerebral arterial spasm: transcranial Doppler ultrasound, cerebral blood flow, and angiographic findings. J Neurosurg 77:575-583, 1992

21. Martin NA, Patwardhan RV, Alexander MJ, Africk CZ, Lee $\mathrm{JH}$, Shalmon E, et al: Characterization of cerebral hemodynamic phases following severe head trauma: hypoperfusion, hyperemia, and vasospasm. J Neurosurg 87:9-19, 1997

22. Nuwer MR, Hovda DA, Schrader LM, Vespa PM: Routine and quantitative EEG in mild traumatic brain injury. Clin Neurophysiol 116:2001-2025, 2005

23. O'Brien NF, Maa T, Yeates KO: The epidemiology of vasospasm in children with moderate-to-severe traumatic brain injury. Crit Care Med 43:674-685, 2015

24. O'Brien NF, Reuter-Rice KE, Khanna S, Peterson BM, Quinto KB: Vasospasm in children with traumatic brain injury. Intensive Care Med 36:680-687, 2010

25. Oertel M, Boscardin WJ, Obrist WD, Glenn TC, McArthur DL, Gravori T, et al: Posttraumatic vasospasm: the epidemiology, severity, and time course of an underestimated phenomenon: a prospective study performed in 299 patients. $\mathbf{J}$ Neurosurg 103:812-824, 2005

26. Provencio JJ, Badjatia N: Monitoring inflammation (including fever) in acute brain injury. Neurocrit Care 21 (Suppl 2):S177-S186, 2014

27. Provencio JJ, Vora N: Subarachnoid hemorrhage and inflammation: bench to bedside and back. Semin Neurol 25:435444, 2005

28. Ract C, Le Moigno S, Bruder N, Vigué B: Transcranial Doppler ultrasound goal-directed therapy for the early management of severe traumatic brain injury. Intensive Care Med 33:645-651, 2007

29. Rosenthal G, Sanchez-Mejia RO, Phan N, Hemphill JC III, Martin C, Manley GT: Incorporating a parenchymal thermal diffusion cerebral blood flow probe in bedside assessment of cerebral autoregulation and vasoreactivity in patients with severe traumatic brain injury. J Neurosurg 114:62-70, 2011

30. Shahlaie K, Keachie K, Hutchins IM, Rudisill N, Madden LK, Smith KA, et al: Risk factors for posttraumatic vasospasm. J Neurosurg 115:602-611, 2011

31. Sloan MA, Haley EC Jr, Kassell NF, Henry ML, Stewart SR, Beskin RR, et al: Sensitivity and specificity of transcranial Doppler ultrasonography in the diagnosis of vasospasm following subarachnoid hemorrhage. Neurology 39:1514-1518, 1989

32. Stein S, Le Roux P: Traumatic vasospasm. Acta Neurochir Suppl 104:427-432, 2008

33. Vespa PM, Nuwer MR, Juhász C, Alexander M, Nenov V, Martin N, et al: Early detection of vasospasm after acute subarachnoid hemorrhage using continuous EEG ICU monitoring. Electroencephalogr Clin Neurophysiol 103:607-615, 1997

34. Vora YY, Suarez-Almazor M, Steinke DE, Martin ML, Findlay JM: Role of transcranial Doppler monitoring in the diagnosis of cerebral vasospasm after subarachnoid hemorrhage. Neurosurgery 44:1237-1248, 1999

35. Washington CW, Zipfel GJ: Detection and monitoring of vasospasm and delayed cerebral ischemia: a review and assessment of the literature. Neurocrit Care 15:312-317, 2011

36. Westermaier T, Pham M, Stetter C, Willner N, Solymosi L, Ernestus RI, et al: Value of transcranial Doppler, perfusion$\mathrm{CT}$ and neurological evaluation to forecast secondary ischemia after aneurysmal SAH. Neurocrit Care 20:406-412, 2014

37. Wilkins RH, Odom GL: Intracranial arterial spasm associated with craniocerebral trauma. J Neurosurg 32:626-633, 1970

38. Wintermark M, Ko NU, Smith WS, Liu S, Higashida RT, 
Dillon WP: Vasospasm after subarachnoid hemorrhage: utility of perfusion CT and CT angiography on diagnosis and management. AJNR Am J Neuroradiol 27:26-34, 2006

39. Wintermark M, Sincic R, Sridhar D, Chien JD: Cerebral perfusion CT: technique and clinical applications. J Neuroradiol 35:253-260, 2008

40. Zhang H, Zhang B, Li S, Liang C, Xu K, Li S: Whole brain $\mathrm{CT}$ perfusion combined with CT angiography in patients with subarachnoid hemorrhage and cerebral vasospasm. Clin Neurol Neurosurg 115:2496-2501, 2013

41. Ziegler DW, Cravens G, Poche G, Gandhi R, Tellez M: Use of transcranial Doppler in patients with severe traumatic brain injuries. J Neurotrauma 14 (Suppl 1):P292, 2010

42. Zubkov AY, Lewis AI, Raila FA, Zhang J, Parent AD: Risk factors for the development of post-traumatic cerebral vasospasm. Surg Neurol 53:126-130, 2000

\section{Disclosures}

The authors report no conflict of interest concerning the materials or methods used in this study or the findings specified in this paper.

\section{Author Contributions}

Conception and design: Al-Mufti, Al-Marsoummi, Alzubaidi. Acquisition of data: all authors. Analysis and interpretation of data: Al-Mufti, Amuluru, Changa, Lander, Patel, Wajswol, Alzubaidi, Singh, Nuoman, Gandhi. Drafting the article: AlMufti, Amuluru, Changa, Lander, Patel, Wajswol, Al-Marsoummi, Singh, Nuoman, Gandhi. Critically revising the article: all authors. Reviewed submitted version of manuscript: Al-Mufti, Al-Marsoummi, Alzubaidi, Singh, Nuoman, Gandhi. Approved the final version of the manuscript on behalf of all authors: AlMufti. Administrative/technical/material support: Al-Mufti. Study supervision: Al-Mufti, Singh, Nuoman, Gandhi.

\section{Supplemental Information Current Affiliations}

Dr. Gandhi: Department of Neurosurgery, Westchester Medical Center, New York Medical College, Valhalla, New York.

\section{Correspondence}

Fawaz Al-Mufti, Rutgers University, Robert Wood Johnson Medical School, 125 Patterson St., Ste. 6100, New Brunswick, NJ 10032. email: fawazalmufti@outlook.com. 